\title{
Final Report for LDRD Project 94-ERD-037: Multi-scale Atmospheric Simulation System
}

\author{
M.M. Bradley \\ H.-N. Chin \\ M.J. Leach \\ J.R. Albritton \\ J. Kong \\ D.L. Ermak
}

January 20, 1997

This is an informal report intended primarily for internal or limited external distribution. The opinions and conclusions stated are those of the author and may or may not be those of the Laboratory.

Work performed under the auspices of the U.S. Department of Energy by the Lawrence Livermore National Laboratory under Contract W-7405-ENG-48. 


\section{DISCLAIMER}

This document was prepared as an account of work sponsored by an agency of the United States Government. Neither the United States Government nor the University of California nor any of their employees, makes any warranty, express or implied, or assumes any legal liability or responsibility for the accuracy, completeness, or usefulness of any information, apparatus, product, or process disclosed, or represents that its use would not infringe privately owned rights. Reference herein to any specific commercial product, process, or service by trade name, trademark, manufacturer, or otherwise, does not necessarily constitute or imply its endorsement, recommendation, or favoring by the United States Government or the University of California. The views and opinions of authors expressed herein do not necessarily state or reflect those of the United States Government or the University of California, and shall not be used for advertising or product endorsement purposes.

This report has been reproduced directly from the best available copy.

Available to DOE and DOE contractors from the Office of Scientific and Technical Information

P.O. Box 62, Oak Ridge, TN 37831

Prices available from (615) 576-8401, FTS 626-8401

Available to the public from the

National Technical Information Service

U.S. Department of Commerce 5285 Port Royal Rd.,

Springfield, VA 22161 


\title{
Final Report for LDRD Project 94-ERD-037: Multi-scale Atmospheric Simulation System
}

\author{
Michael M. Bradley, Hung-Neng (Steve) Chin, Martin J. Leach, \\ James R. Albritton, Jun Kong, and Donald L. Ermak
}

\section{PURPOSE}

The purpose of this LDRD project was to develop a multi-scale atmospheric simulation system that could be applied to a diverse range of atmospheric problems, including key research issues related to global and regional climate change, studies of regional and local precipitation, and emergency predictions of the path and exposure concentrations of toxic materials released into the atmosphere. In addition to its multi-scale nature, the new simulation system was to be designed such that the individual components of the system could be selected by users in an optimal way to support the research and operational needs of the entire Atmospheric Sciences Division (ASD).

To develop such a model -- one that can be used for basic research and for real-time emergency response, and can simulate the processes within a cloud as well as the weather over the western United States -- is a significant challenge. Both research and operational problems often involve the interaction of atmospheric processes on several length scales (ranging from $10^{-7}$ to $10^{7}$ meters). However, most numerical models of the atmosphere are confined to representing one or, at best, two scales because of computer limitations, mathematical approximations, and restrictive coordinate systems. Many modelers accept scale-specific equation sets to achieve gains in computational speed, resolution, or domain size, but the real atmosphere does not recognize scale boundaries, and numerical models based on the old scaling arguments are incapable of simulating many processes of current, high priority research interest. Important examples include the wide range of cloud-climate feedback mechanisms suspected by several prominent researchers (Lindzen, Ramanathan, Twomey) to be critical in the atmosphere's response to greenhouse gases and aerosols, and orographic (terrain) effects of distant mountain ranges on local weather far downwind. Scale interactions are also important for operational meteorological problems, such as predicting the long-range atmospheric transport and dispersion of radionuclides injected into the upper atmosphere by a hot plume from an explosion, e.g., the Chernobyl disaster. 


\section{ACTIVITIES}

\section{General Technical Approach}

We have addressed this problem by developing a multi-scale atmospheric simulation system that includes hydrostatic (currently operational) and nonhydrostatic (soon to be operational) dynamics, multiple-level grid nesting, user-selectable coordinate systems, and user-selectable physics modules. To accelerate the development process and to establish a long-term collaboration with another research institution, we decided to use existing models as the core dynamic drivers for the new system. We started with a list of approximately 20 candidate models from around the world, invested several months in model evaluations, and selected the Naval Research Laboratory's (NRL) Navy Operational Regional Atmospheric Prediction System (NORAPS) and Coupled Ocean Atmosphere Mesoscale Prediction System (COAMPS).

NORAPS is a robust, proven model and has been used by the Navy as an operational forecast model for several years. It can be set up for an arbitrary location anywhere in the world, initialized with output from a global model, and run to produce a forecast for the selected location. NORAPS is a primitive equation (hydrostatic) model with a split-explicit time integration, sigma coordinates with variable resolution in the vertical, and options for up to three levels of grid nesting in the horizontal. The model's physics includes a 1.5-order TKE (Turbulent Kinetic Energy, as quantified by a grid-volume averaged, subgrid-scale prognostic perturbation kinetic energy equation) closure scheme, large-scale precipitation representation, dry convective adjustment, and a modified Kuo cumulus parameterization scheme. The split-explicit scheme allows NORAPS to achieve an impressive computational speed by using a special solver for rapidly propagating waves.

COAMPS is a nonhydrostatic model, and will soon replace the NORAPS model for many of the Navy's forecasting needs. Because COAMPS is nonhydrostatic, it can be applied to all cases that NORAPS can simulate and also can use a much finer grid resolution to simulate small-scale phenomena involving non-negligible vertical velocities, such as convective storms and the airflow over short-wavelength terrain. COAMPS is an advanced mesoscale model with improved data assimilation methods, better boundary layer physics, and cloud-scale microphysics. Although currently slower than NORAPS, NRL and LLNL are committed to making COAMPS as computationally efficient as possible. COAMPS has been developed to "look like" NORAPS with regard to model input and output characteristics. This greatly facilitates the integration of the two drivers 
into a single simulation system with common input streams, post-processing graphical packages, etc. Our multi-scale simulation system will allow the user to access both the hydrostatic (NORAPS) and nonhydrostatic (COAMPS) dynamic drivers.

We have been transferring our own unique physics modules into the new simulation system. Our current version of NORAPS includes our own soil physics module, sub-gridscale and grid-scale cloud parameterization module, and modifications to the radiation physics. Modules from other sources can be continually added as research emphases change and as new parameterizations are developed. New modules may originate from LLNL, NRL, or other collaborating research institutions. Not only will the system architecture allow the user to select specific modules for different physical processes, but it will also allow the user to select different modules representing the same physical process. For example the user will be able to choose from several different parameterizations of convective cloud processes.

This was a very high leverage project. The greatest synergisms were with the ARAC-3 project, which provided essential data acquisition, data assimilation, and post-processing capabilities for the multi-scale simulation system at no cost to the LDRD Program. ARAC-3, in turn, will use the NORAPS and COAMPS models, acquired and improved under this LDRD project, to produce prognostic wind fields to drive its new dispersion model. In addition, ASD's precipitation and hydrology research will use the new system. This will provide us the opportunity to compare simulations done with the new system with comparable simulations done with our old models.

There are only a few models in the world that approach the simulation capabilities of our new simulation system. Most of these models were evaluated in our search for core dynamic drivers. Each one had shortcomings and none would fulfill our requirements in its current state. We believe that it is essential for LLNL and DOE to possess their own multi-scale atmospheric simulation system, developed and maintained by LLNL scientists, capable of being modified to address unforeseen future challenges, and available for both unclassified and classified projects. The development of this new capability substantially enhances the Laboratory's ability to address important environmental issues. The new simulation system will be the primary research tool for ASD well into the twenty-first century, and will enable us to be extremely competitive for research grants. 


\section{The Addition of New Capabilities of the System}

New Physics Capabilities and Their Application to a Major California Winter Storm

We have made several major modifications to the physical parameterizations in NORAPS. Because the Navy is most interested in rapid, real time forecasts for various points around the world, the physics packages originally in NORAPS were highly simplified. However, because LLNL scientists are more interested in researching the interaction of physics with dynamics and local forcing, we decided to include more detailed physics packages into our version of NORAPS.

First, we included a cloud physics package. Originally NORAPS had a simple largescale condensation scheme, i.e., if a grid point relative humidity exceeded a specified threshold value (normally 90\%), all water above that value was condensed and rained out. This type of scheme tends to produce too much precipitation. For example, Figure 1 shows the precipitation accumulated during a frontal passage over a 24-hour period ending at $00 \mathrm{Z}$ on March 10 (1600 March 9 local time), 1995 as predicted by the original version of NORAPS. The values along the peaks of the Sierra Nevada are as large as 11 inches of equivalent water, or about 10-12 feet of snow. Figure 2 shows observed precipitation amounts for the same 24-hour period. Note that the actual values are considerably less than those predicted by the original NORAPS model.

The cloud microphysics scheme we added to NORAPS (Rutledge and Hobbs, 1984) includes 5 categories of water: water vapor, cloud liquid water, rain, cloud ice and snow. The transformation among the various categories are essentially a set of coupled ordinary differential equations with assumed hydrometeor size distributions. The rate for conversion between categories depend on the distribution and have been derived from various laboratory and field measurements. The simulated precipitation from the new cloud microphysics physics scheme is shown in Figure 3. While the basic spatial distribution is similar to the simple condensation scheme, the amounts are less by a factor of 2 to 3 and are more realistic and closer to the observed values. In addition to the Rutledge and Hobbs microphysical scheme, Chin's scheme (Chin 1994, Chin et al. 1995) is available for use in NORAPS. This scheme has been used to simulate both midlatitude and tropical squall-line systems with prominent anvils and radar-observable mesoscale structures, such as bright melting bands and transition zones. 
After the cloud physics scheme was added, the radiative transfer was modified to account for the presence of liquid- and ice-phase hydrometeors. The modified Harshvardhan (1987) long- and shortwave radiation transfer schemes (Chin 1994; Chin et al. 1995) were implemented in NORAPS, and preliminary testing was completed. Realistic treatment of radiative transfer is important to get the three dimensional heating, resulting in the proper storm structure. In Figure 4, the 0001Z 11 March (1601 10 March local time) 1995 infrared GOES satellite image shows the clouds over the western portion of the United States with the southeasterly-moving frontal system extending southwest over the Pacific Ocean from Southern California. The LLNL NORAPS forecast cloud water is shown in Figure 5. This is a much smaller domain than shown in the satellite image; the northern extent is near the Oregon/California border and the southern border extends just into Baja California. Clouds exist over most of the eastern portion of the domain with the frontal structure also extending to the southwest from Southern California. A corresponding prognostic cloud water plot cannot be produced by the original NORAPS, because that version does not have a prognostic equation for cloud water (a capability recently developed by Albritton for NORAPS diagnoses "precipitable water", from which approximate cloud distributions may be inferred). By including cloud microphysics and the interaction with radiative transfer, we can more realistically simulate the structure and dynamics of the storm system and also simulate regional climate.

Finally, we added more detailed land surface processes (Pan and Mahrt, 1984). The land surface processes are critical for both short- and long-term simulation. We included a two-layer model: a deep soil layer and a near surface layer. The model includes both temperature and moisture. The deep soil layer, normally initialized with climatological values, communicates with the near surface layer. The near surface layer exchanges both heat and moisture with the atmosphere through the sensible and latent heat fluxes that are part of the surface energy balance. The observed temperature at Bakersfield, CA (BFL) is shown in Figure 6 for a 72 hour period beginning March 8 at 00Z, 1995. For comparison, the forecast temperature with the original NORAPS (Figure 7a) and the updated version (Figure 7b) are shown. With the updated version, the maximum temperatures are very close to the observed, almost $2 \mathrm{~K}$ greater than the original NORAPS forecast. However the minimum temperatures from the original are closer to the observed. We continue to examine the effects of the physics package upgrades on the forecast of temperature, as well as precipitation storm structure, etc. The land surface process package provides an important link: the system can now be used for applications beyond traditional meteorology, such as regional climatology and hydrology. 
These physics upgrades to NORAPS allow scientists to study in greater depth the interactions between the physics and dynamics that constitute atmospheric flows and storm systems. We have been using the modified version of NORAPS for simulation studies of the amount, type, and distribution of precipitation in the winter storms that occurred in California during January and March of 1995 and March of 1996. Using the new physics package, we have assessed the interaction of small-scale circulations imbedded within storm systems with the terms of the water budget. We have been able to simulate more detailed and realistic flow fields, precipitation amounts, and spatial distributions of precipitation than was possible with the original NORAPS code.

\section{$\underline{\text { New Model Initialization and Boundary Condition Capabilities }}$}

As an example of the LDRD's synergism with the ARAC Program, the LLNL version of NORAPS has been modified to include new features that are more relevant to the ARAC operational environment. The original NORAPS derived its initial and boundary data exclusively from NOGAPS, the Navy's Global Analysis and Prediction System. We have extended our version of NORAPS to ingest gridded data from the NCEP's (National Center for Environmental Programs, formerly the National Meteorological Center) global (AVN model) and continental (ETA model) forecasts. The importance of the 40-kmresolution ETA model forecasts is evident from a recent modeling study by Mesinger (1996), which indicates that a model's precipitation forecasting skill substantially increases with finer resolution input data, particularly for intense precipitation events.

\section{New, Finer Spatial Resolution Capability}

While the Navy's operational applications of NORAPS are typically at grid resolutions of $45 \mathrm{~km}$ or greater, our version of NORAPS has be modified to ingest topographic and land/water data at a $2 \mathrm{~km}$ grid resolution in order to capture the details of the geography at much finer scales. This modification will be useful for both research applications and ARAC operational applications, and is another product of the synergistic cooperative effort with ARAC.

\section{Ongoing Model Development}

\section{New Data Assimilation Capability}

We are currently extending the data assimilation capabilities in NORAPS by implementing algorithms to ingest currently undistributed local mesonet data, such as 
observations from meteorological towers, profilers, and surface stations. This work is part of a larger effort being undertaken by a consortium of institutions in the greater San Francisco Bay Area. The consortium is pooling resources to develop a mesonet system with which real-time meteorological data can be accessed to enhance forecasting and modeling efforts.

\section{Additional Radiation Transfer Scheme}

$\mathrm{Fu}$ and Liou's (1993) radiation scheme (the highest state-of-the-art in physics, particularly in the treatment of cloud optical properties) with a significantly improvement computational scheme has been recently delivered to the Atmospheric Physics group through the Chin-Fu collaboration, and is ready to be implemented in NORAPS.

\section{New Cumulus Convection Scheme}

The well tested Emanuel cumulus parameterization scheme (1991) is ready for implementation in NORAPS. This scheme is expected to enhance NORAPS's generality due to the inclusion of downdraft effects from the cumulus clouds. See section entitled $A n$ Examination of Hybrid Cloud Parameterization Schemes.

\section{The Hybrid Method of Cloud Parameterization for Regional-Scale Simulations}

The hybrid method of cloud parameterization refers to the coupling of an explicit ice microphysics scheme with an implicit cumulus parameterization in a meso-scale (or regional-scale) model. The importance of this approach to handle convective and stratiform precipitation has been discussed in the literature (i.e., Cohen and Frank 1987; Zhang et al. 1988; Zhang 1989). However, the use of a convective-scale version of explicit microphysics scheme in meso-scale applications imposes substantial uncertainties for the auto-conversion and collection processes due to their scale dependence. These uncertainties eventually impact the whole microphysical behavior. To solve this problem, a mesoscale version of Chin's microphysics scheme and its interaction with a cumulus parameterization scheme is ready to be implemented in NORAPS. See section entitled An Examination of Hybrid Cloud Parameterization Schemes.

\section{An Examination of Hybrid Cloud Parameterization Schemes}

Many cumulus parameterization schemes have been used in regional-scale atmospheric research, and it is important to understand how differences in physics and grid resolution 
affect the performance of these different schemes in regional climate simulations. Understanding these effects can help us improve regional-scale forecasts of hydrological events, ranging from floods to multi-year fluctuations in the water supply. Unfortunately, the limitations and the validity of individual schemes have not been adequately studied. In this study we compared results from the modified Kuo scheme (Anthes et al. 1987), as used in the original NORAPS model, with the more sophisticated Emanuel cumulus parameterization scheme (1991). The Kuo scheme is the one of the few currently used schemes that does not consider the effects of downdrafts on the larger-scale environment. The Emanuel scheme, on the other hand, contains quite complete physics, was designed to work in both meso- and large-scale models, and is much more computationally efficient than other commonly used schemes such as Arakawa-Schubert.

To test the extreme bound of convective downdraft effects in the cumulus parameterization schemes, we selected a midlatitude summer-time squall-line system for our case study . A benchmark solution for the squall-line system was produced using Chin's nonhydrostatic cloud model (Chin 1989; Chin 1994; Chin et al. 1995; Chin 1996; Chin and Wilhelmson 1996) with an explicit ice microphysics scheme. Then the hybrid cloud parameterization (the Emanuel cumulus scheme and Chin's mesoscale version of a bulk microphysics scheme) was used in Chin's 2-D nonhydrostatic mesoscale model, and its performance was evaluated by comparison with results from the explicit cloud model. To simplify the evaluation, radiation effects were not included. As seen Fig. 8a, the cloud model (with $\Delta \mathrm{x}=2 \mathrm{~km}$ ) simulated an eastward propagating rainband with a speed of $15 \mathrm{~m}$ $\mathrm{s}^{-1}$; this was documented by observations. The Emanuel scheme in the nonhydrostatic mesoscale model (with $\Delta \mathrm{x}=20 \mathrm{~km}$ ) produced a similar propagating rainband (Fig. $8 \mathrm{~b}$ ), but with at a faster speed $\left(18 \mathrm{~m} \mathrm{~s}^{-1}\right)$.

The fundamental mechanism to develop the rainband is the lifting associated with the interaction between the pool of cold air on the ground and the vertical shear of the horizontal wind. The original NORAPS model cannot simulate this type of convective system because there is no cumulus downdraft effect in the Kuo scheme.

As the downdraft effect is weakened in the Emanuel scheme, precipitation in the dry meso-scale model (a version of the model with no grid-scale precipitation and no microphysics parameterization) is substantially enhanced (not shown). In addition, precipitation starts from the very beginning of the simulation (too early) in the dry mesoscale model due to the nature of cumulus parameterization scheme, which assumes that rainwater is produced when the cumulus parameterization is turned on and it falls out as 
precipitation to the ground instantly. When the meso-scale version of the ice microphysics scheme is coupled with the Emanuel scheme (this version of the model is referred to as the moist mesoscale model), a similar propagating rainband exists (Fig. 8c), but the precipitation appears after a substantial delay (more realistic timing). The delay is mainly due to the fact that the more realistic hybrid cloud parameterization condenses moisture to first form non-precipitating hydrometeors, and then subsequently forms precipitating hydrometeors.

Comparisons of the cloud model and meso-scale model simulations of the temporallyaveraged dynamical structures at the mature stage of the storm system are shown in Fig. 9. All models exhibit an upshear (westward) tilted updraft core. As a result of water-loading, which offsets the lifting due to latent heat release, the magnitude of the maximum updraft in the moist meso-scale model is weaker than its counterpart in the dry model. This loading effect, however, enhances the downward motion in the moist meso-scale model. The most striking difference between the cloud model and the meso-scale model arises at the vertical structure of horizontal wind. The wind profile in the meso-scale model near the convective region tilts eastward, instead of westward, as simulated by the cloud model. In addition, the upper-level rearward (westward) outflow is weaker than its leading counterpart and the low-level rear-to-front inflow is not simulated at all by the meso-scale models. These shortcomings are primarily due to the lack of momentum transport in the Emanuel scheme, a deficiency that exists in many cumulus parameterization schemes, including the Kuo scheme. To realistically simulate the dynamical structure of convective systems in environments with substantial wind shear, momentum transport by sub-grid cumulus must be included in the regional model. This can be accomplished by adding a simple momentum scheme from earlier published work.

In summary, these results show a significant value of hybrid cloud parameterization schemes for regional-scale modeling. The computational efficiency and scale dependence of the meso-scale microphysics scheme tested here appear to have high value for both operational and research applications.

\section{Technical Outcome}

This LDRD has greatly enhanced the research capabilities of the Atmospheric Sciences Division and the emergency response capabilities of ARAC. The improved NORAPS component of the system is fully operational, has already be used for research applications, and is ingesting real-time weather data and providing real-time weather forecasts on a daily 
basis. The recently acquired COAMPS component is running and ready for implementation. Areas of research applicability using the new LLNL NORAPS-COAMPS simulation system include regional climate, mesoscale circulations, storm dynamics, cloud dynamics and microphysics, cloud-radiation interactions, cloud-aerosol interactions, cloud chemistry, intentional and inadvertent weather modification, atmospheric electricity (with additional physics), orographic storms, air quality, and smoke plume dynamics and microphysics. The new system will have both research and operational applications for flood prediction and to water resource management. It will be a powerful real-time operational resource for the Atmospheric Radiation Advisory Capability (ARAC) -- to provide much more accurate, high-resolution wind fields than were previously available, to improve source term representation (e.g., the Chernobyl explosion), to provide standard benchmarks for ARAC codes, and to develop precipitation scavenging parameterizations. The new system will also have applications to aviation safety and military planning and operations. It will enable us to be very competitive for three-year research grants from DOE's ARM Program, designed to improve the representation of cloud life cycles and cloud-radiation interactions in global climate models. We could also compete for projects funded by NOAA, such as the Tropical Oceans and Global Atmosphere (TOGA) Program, and the Global Energy and Water Cycle Experiment (GEWEX); and for projects funded by NASA.

The success of this LDRD effort has led ARAC to partially support the continuation of the precipitation research by Dr. Martin Leach, and was also instrumental in bringing Dr. Jun Kong to ASD as a University of California Campus-Laboratory Collaborative (UC CLU) Program postdoctoral fellow. Other by-products of this research may lead to a Strategic Initiative proposal to develop a massively parallel version of COAMPS as part of the DOE ASCI (Advanced Strategic Computing Initiative) effort. There is also a possibility that the Office of Naval Research may be interested in supporting Dr. Michael Wehner of ASD to coordinate this effort.

In summary, the LLNL NORAPS-COAMPS system is a powerful, versatile, and evolutionary research tool that can be used by all ASD scientists and all ASD projects. It will facilitate greater collaboration among ASD scientists, because they will all have access to the same simulation system instead of only to their own specialized models, as was previously the case. It will also facilitate major collaborations with NRL as a new research partner, and the system's modular architecture will increase collaborative research between ASD scientists and scientists at universities and other research institutions. The 
consolidation of our modeling capabilities into a single simulation system will reduce costs for code maintenance, graphics support, etc. These positive attributes should result in better science, improved productivity and greater efficiency (compared to the "old way of doing business"), increased collaborative research inside and outside the Laboratory, and new funding from successful proposals using the new system.

\section{Publications and Presentations}

Leach, M.J., J. Kong, H.-N. S. Chin, and S. Soong, 1996: "Modeling Heavy Precipitation Events in California", presented at the May 1996 Meeting of the Campus Laboratory Consortium, Scripps Institute of Oceanography, LaJolla CA.

Lee, R.L., J.R. Albritton, S. Chan, J.M. Leone, J.S. Nasstrom, and G. Sugiyama, 1997: "ARAC-3, A New Generation Emergency Response Modeling System", American Nuclear Society's Sixth Topical Meeting on Emergency Preparedness and Response, San Francisco, CA, April 22-25, 1997. Also LLNL UCRL-JC125043.

Kong, J., M.J. Leach, H.-N. S. Chin, and S. Soong, 1996: "Using the Navy NORAPS model for California Precipitation", presented at the May 1996 Meeting of the Campus Laboratory Consortium, Scripps Institute of Oceanography, LaJolla CA.

Sugiyama, G. and S.T. Chan, 1996: "Meteorological Data Assimilation for Real-Time Emergency Response", American Nuclear Society's Sixth Topical Meeting on Emergency Preparedness and Response, San Francisco, CA, April 22-25, 1997. Also LLNL UCRL-JC-125036

\section{References}

Anthes, R. A., E.-Y. Hsie, and Y-H Kuo, 1987: Description of the Penn State/NCAR Mesoscale Model Version 4 (MM4), NCAR/TN-282+SSTR, National Center for Atmospheric Research, Boulder, CO, 66 pp.

Chin, H.-N. S., 1994: The impact of the ice phase and radiation on a midlatitude squall line. J. Atmos. Sci., 51, 3320-3343.

Chin, H.-N. S., and Y. Ogura, 1989: Supplementary modeling study of a tropical convective band. J. Atmos. Sci., 46, 1440-1447.

Chin, H.-N. S., Q. Fu, M. M. Bradley, and C. R. Molenkamp, 1995: Modeling of a tropical squall line in two dimensions: Sensitivity to radiation and comparison with a midlatitude case. J. Atmos. Sci., 52, 3172-3193.

Chin, H.-N.S. and R.B. Wilhelmson, 1996: Modeling of a tropical squall line within moderate CAPE and a strong low-level jet. J. Atmos. Sci. (accepted; in final review). 
Cohen, C., and W. M. Frank, 1987: Simulation of tropical convective systems. Part II: Simulations of moving cloud lines. J. Atmos. Sci., 44, 3800-3820.

Emanuel, K. E., 1991: A scheme for representing cumulus convection in large-scale models. J. Atmos. Sci., 48, 2313-2335.

$\mathrm{Fu}, \mathrm{Q}$, and K.-N. Liou, 1993: Parameterization of the radiative properties of cirrus clouds. J. Atmos. Sci., 50, 2008-2025.

Harshvardhan, R. Davies, D. A. Randall, and T. G. Corsetti, 1987: A fast radiation parameterization for atmospheric circulation models. J. Geophys. Res., 92, 10091016.

Mahrt, L. and H.-L. Pan, 1984: A two-layer model of soil hydrology. Bound. Layer Met., 29, 1-20.

Mesinger, F., 1996: Improvements in quantitative precipitation forecasts with the ETA regional model at the National Center for Environmental Prediction: The 40-km upgrade. Bull. of Amer. Meteor. Soc., 77, 637-649.

Rutledge, S.A. and P.V. Hobbs, 1984: The mesoscale and microscale structure and organization of clouds and precipitation in midlatitude cyclones. XII: a diagnostic modeling study of precipitation development in narrow cloud-frontal rainbands. $J$. Atmos. Sci., 41, 2949-2972.

Zhang, D. L., 1989: The effect of parameterized ice microphysics on the simulation of vortex circulation with a mesoscale hydrostatic model. Tellus, 41A, 132-147.

Zhang, D.-L., E.-Y. Hsie, and M. W. Moncrief, 1988: A comparison of explicit and implicit predictions of convective and stratiform precipitating weather systems with a meso-B scale numerical model. Quart. J. Roy. Meteor. Soc., 114, 31-60. 


\section{Figure Captions}

Figure 1. The original NORAPS model's predicted accumulated precipitation (in inches), for the 24-hour period ending at 0000Z, March 10 (1600 March 9 local time), 1995.

Figure 2. Observed accumulated precipitation (in inches) for the same time period shown in Figure 1.

Figure 3. As in Figure 1, but using LLNL's new version of the NORAPS model with the cloud microphysics parameterization of Rutledge and Hobbs (1984).

Figure 4. Infrared GOES satellite image showing the clouds over the western United States at 0001Z on March 11 (1601 March 10 local time), 1995.

Figure 5. LLNL-NORAPS-predicted cloud distribution corresponding to the satelliteobserved cloud distribution shown in Figure 4.

Figure 6. Observed surface temperature at Bakersfield, CA for the 72-hour period beginning 0000Z March 8 (1600 March 7 local time), 1995.

Figure 7. Predicted surface temperature at Bakersfield, CA for the same time period (the $x$-axes is Julian Day) shown in Figure 6 for (a) the original NORAPS model, and (b) the LLNL-NORAPS model with the land surface parameterization of Pan and Mahrt (1984). 
NORAPS grid $1,91 \times 91 \times 36 \quad 13.50 \mathrm{~km}$ surface ttl prep

48 h 0 m forecast valid at 1995031000 from 1995030800

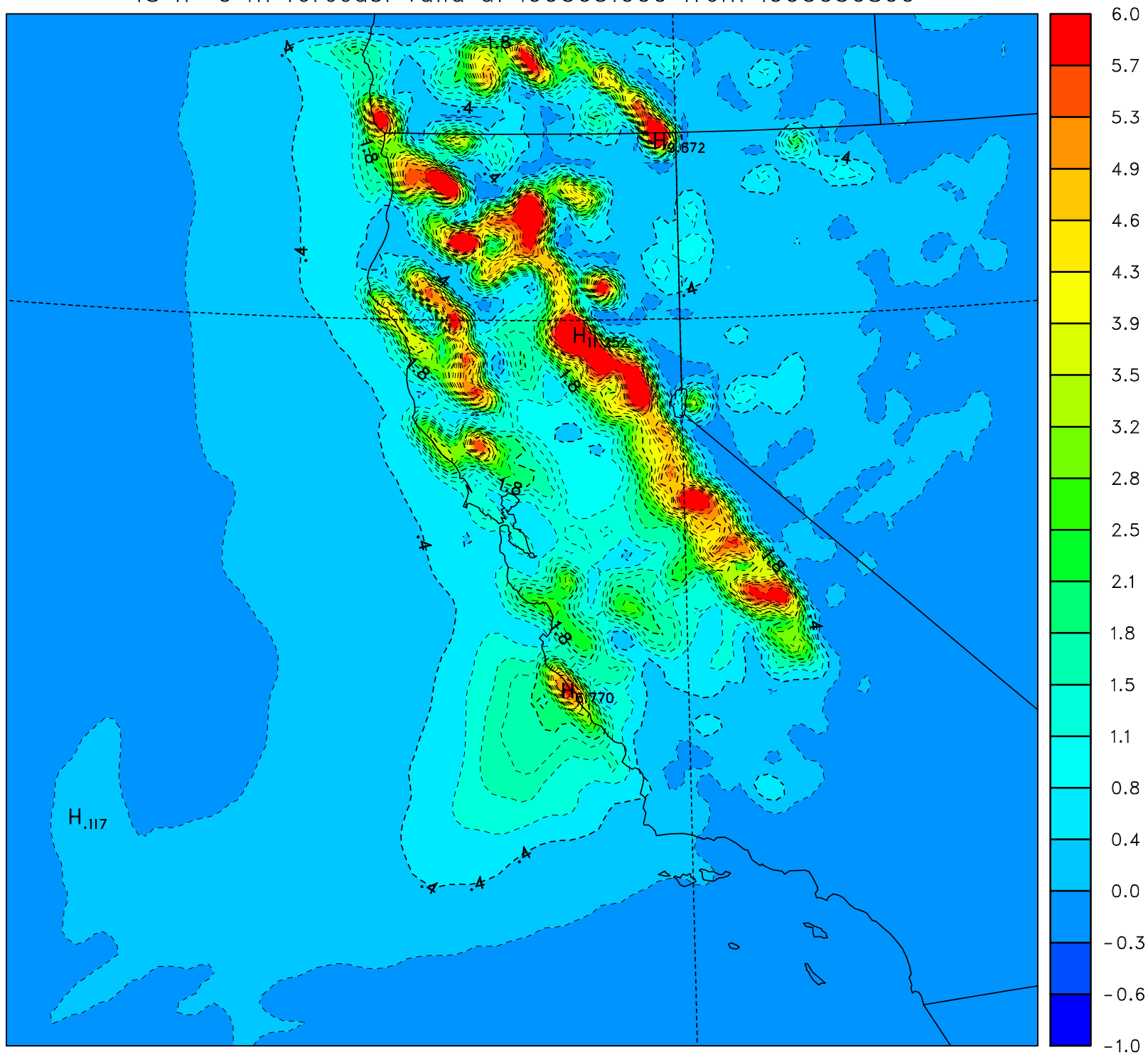


24 hr acc precip 10/0

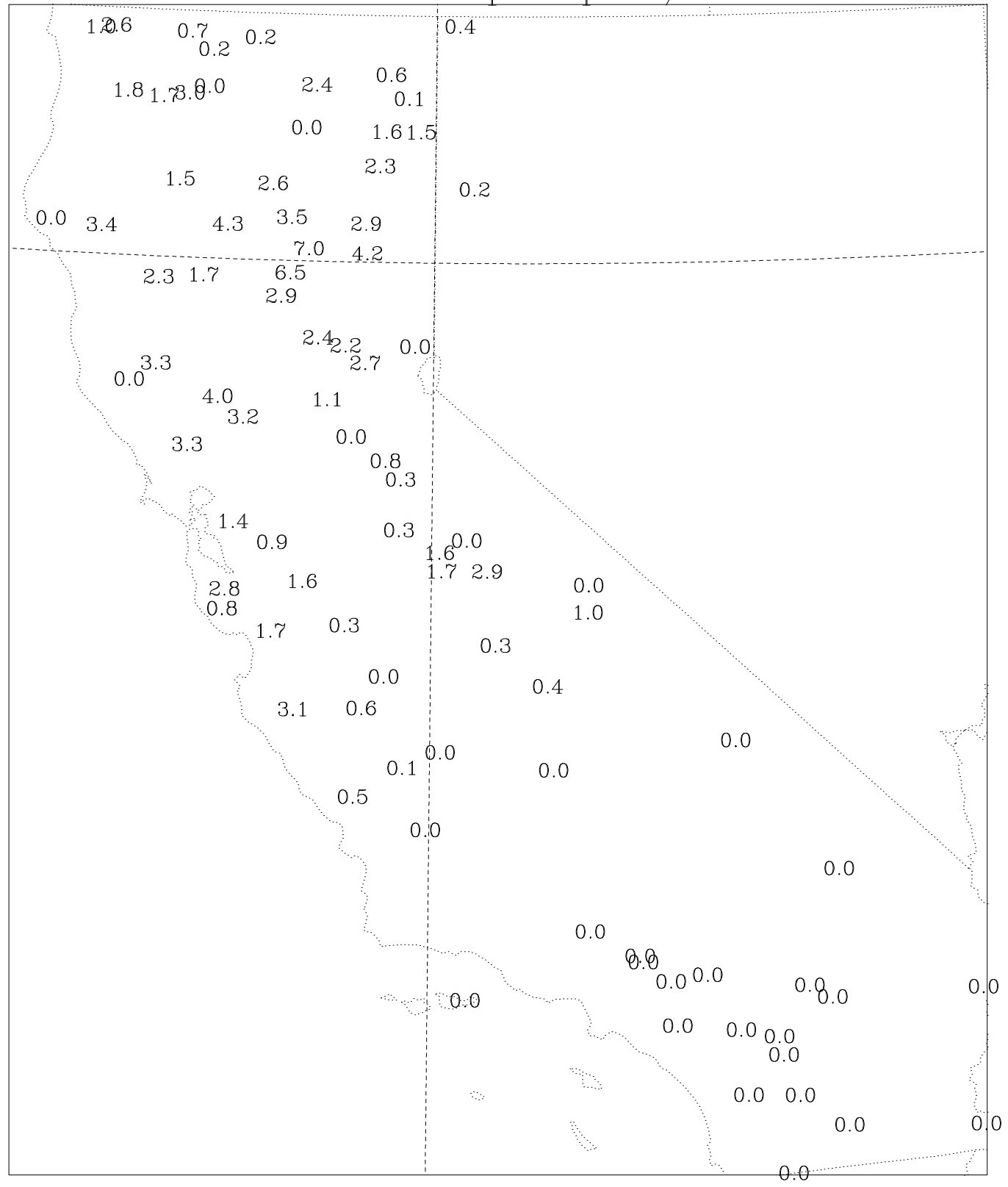



NORAPS grid $1,91 \times 91 \times 36 \quad 13.50 \mathrm{~km}$ surface ttl prep

48 h 0 m forecast valid at 1995031000 from 1995030800

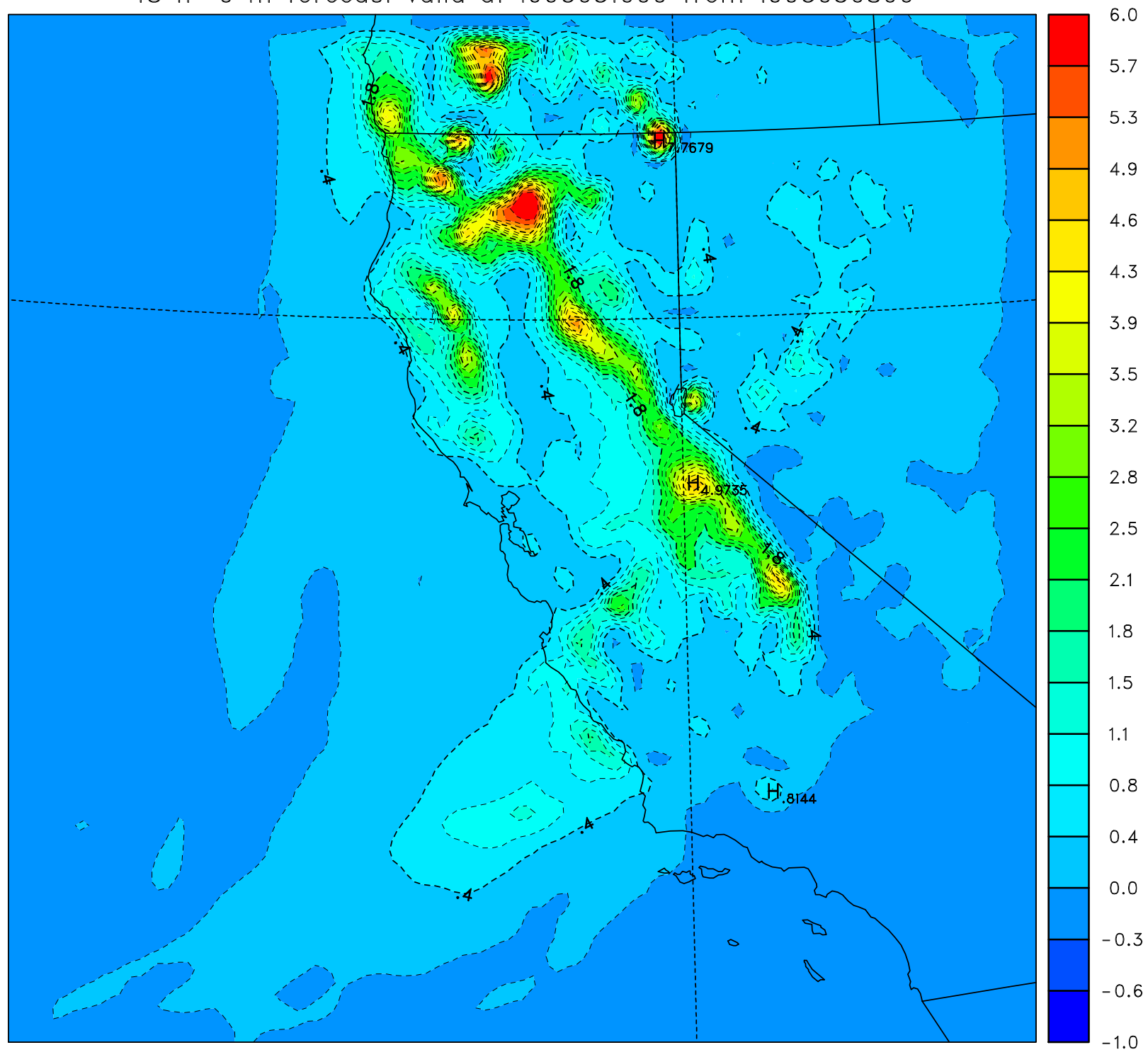




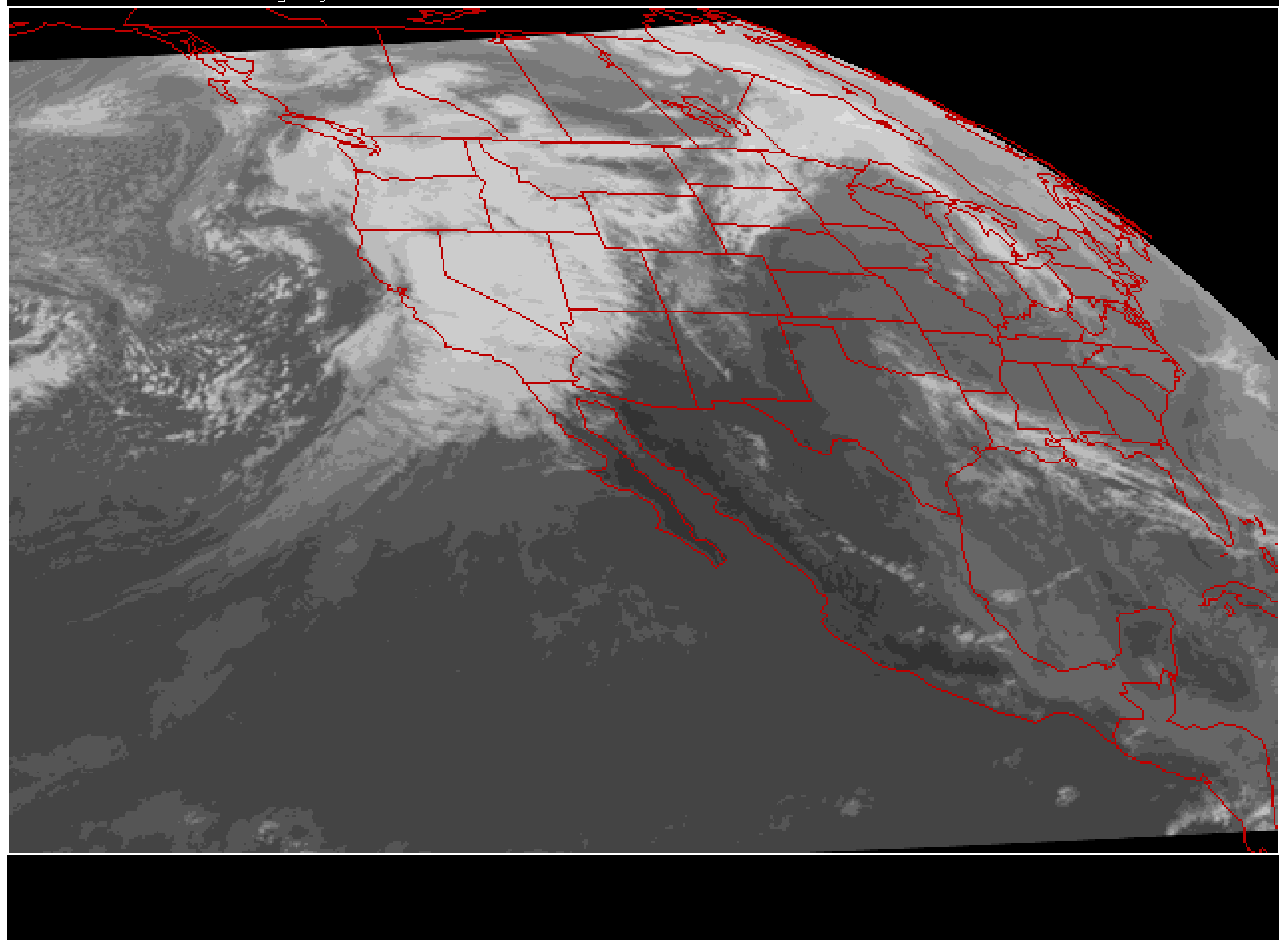




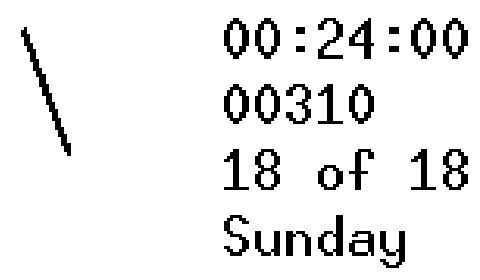

N

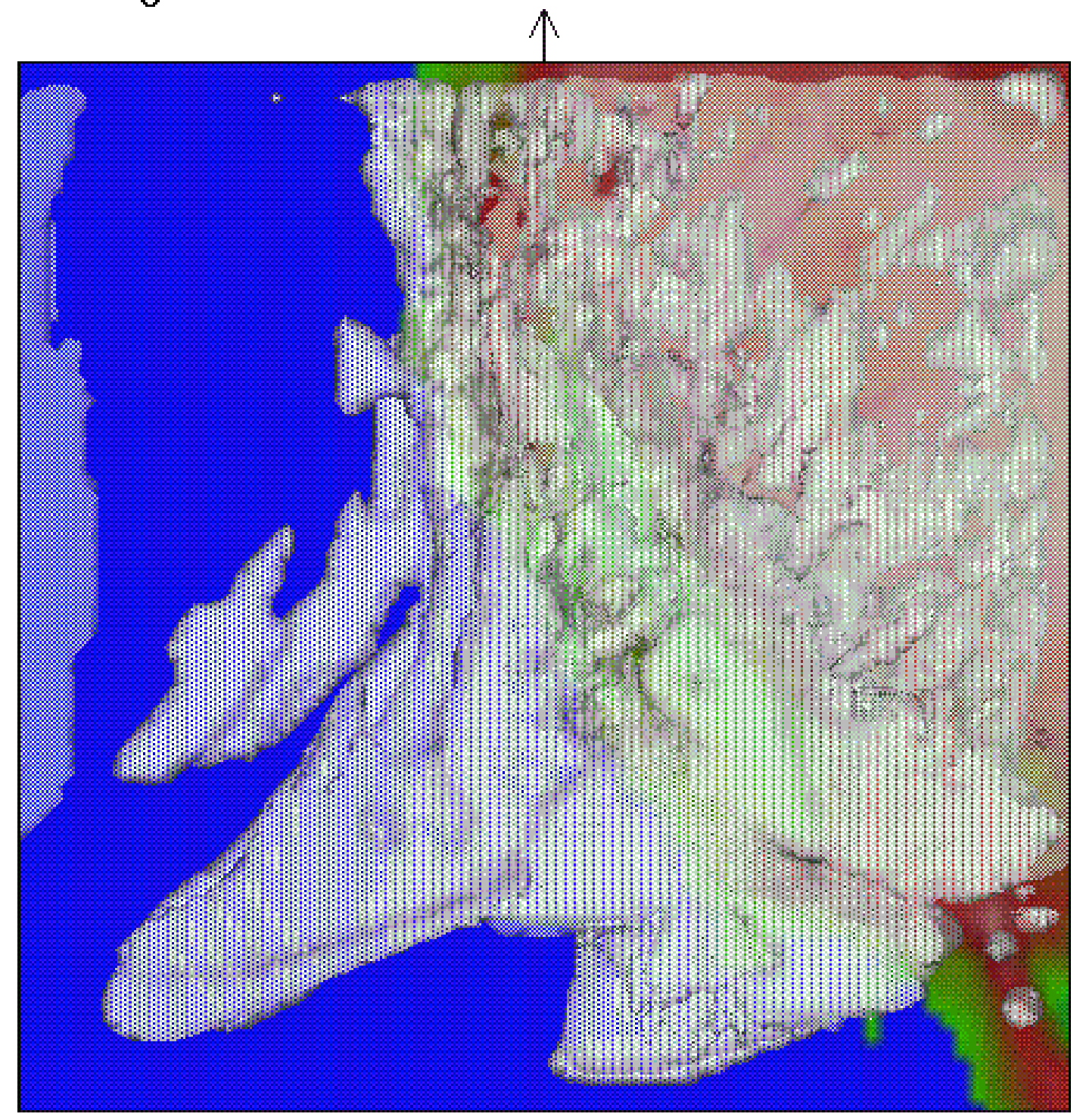

Vis5D 


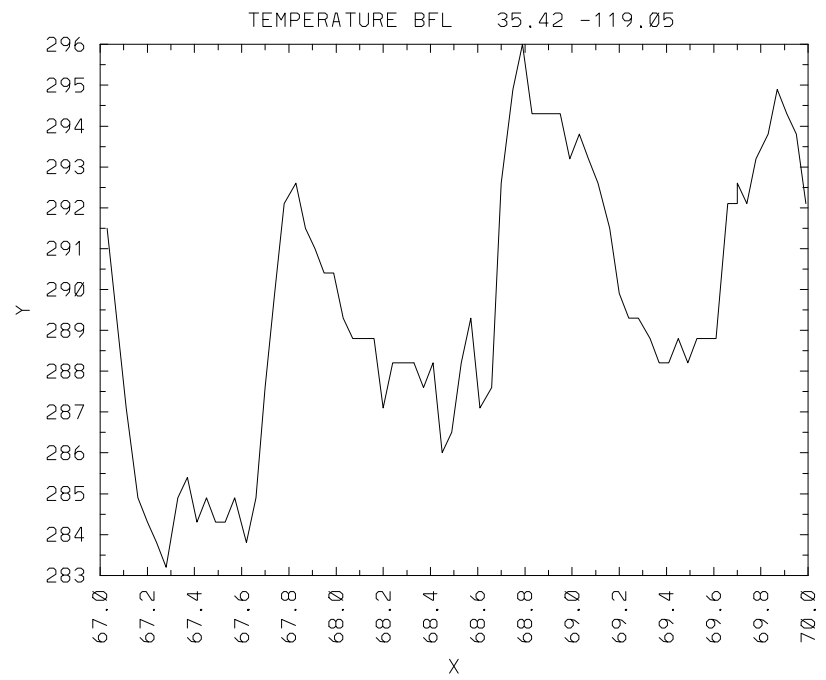



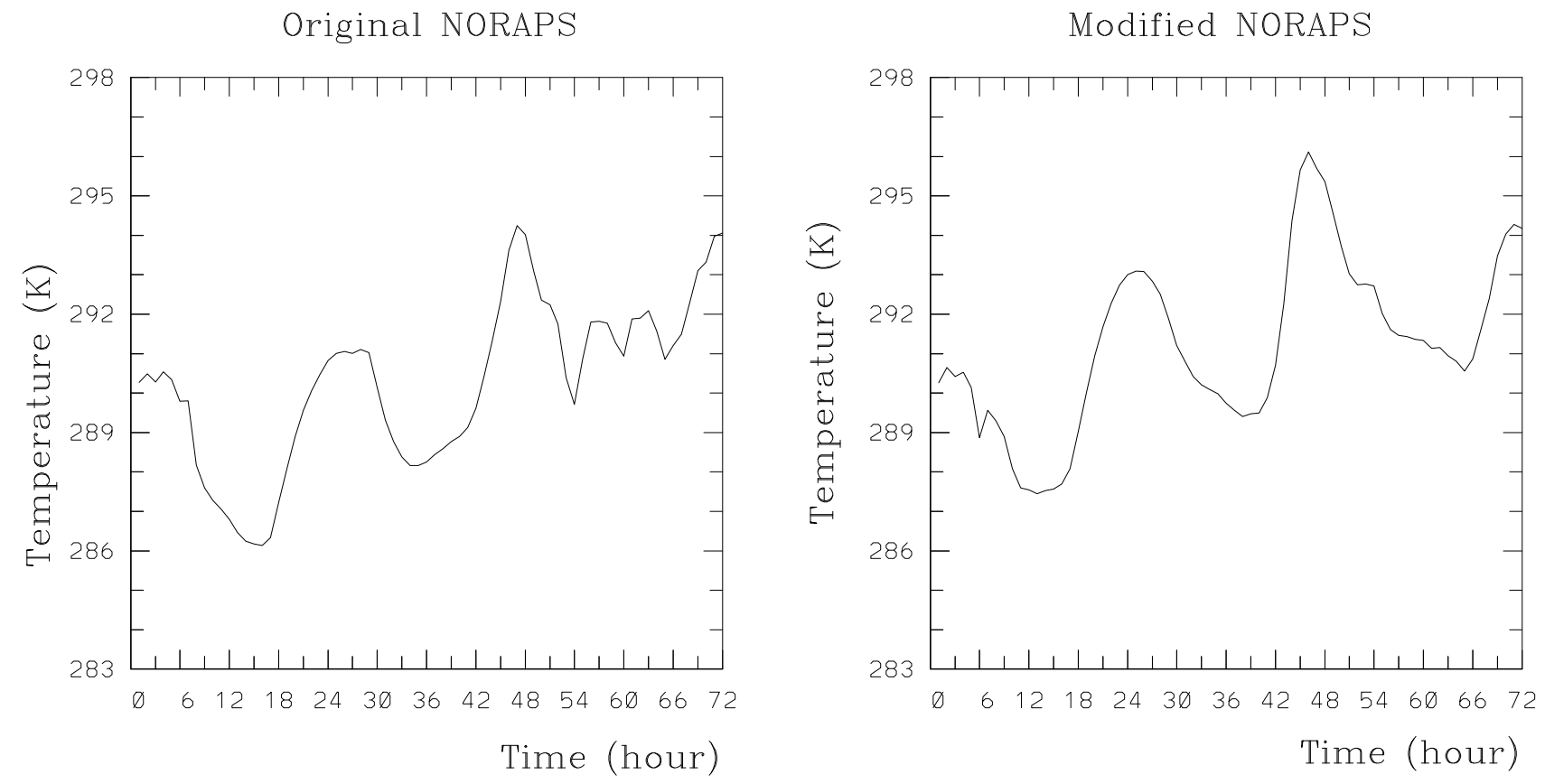


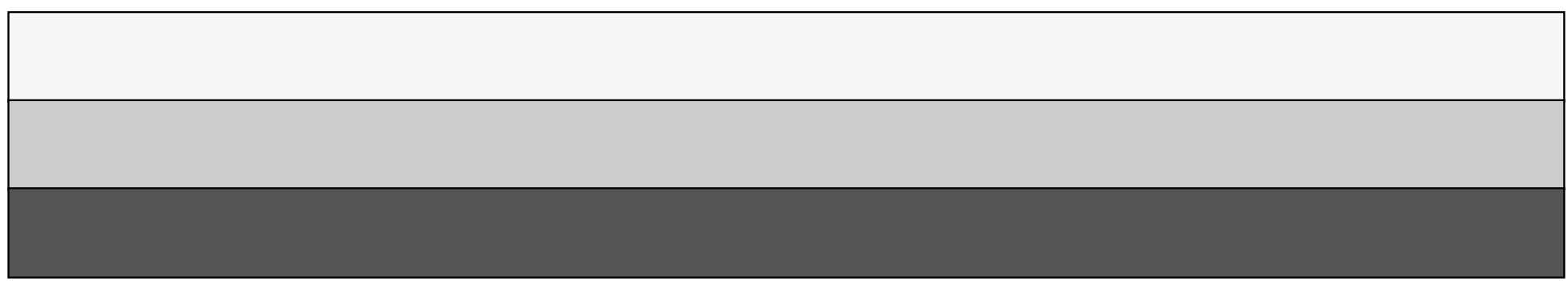

